\title{
Intranasal endoscopic prelacrimal recess approach for maxillary sinus inverted papilloma
}

\author{
Qian-Qian Yu ${ }^{1} \cdot$ Ge Guan $^{2}$ - Nian-Kai Zhang ${ }^{1} \cdot$ Xiao-Wen Zhang $^{1} \cdot$ Yan Jiang ${ }^{1} \cdot$ Yuan-Yuan Lian ${ }^{1} \cdot$ Ting-Ting Liu $^{1}$. \\ Xiao-Dan Jiang ${ }^{1} \cdot \mathrm{Na} \mathrm{Li}^{1} \mathbb{C}$
}

Received: 23 May 2018 / Accepted: 25 July 2018 / Published online: 4 August 2018

(c) The Author(s) 2018

\begin{abstract}
Purpose This study aims to determine the indications and effectiveness of transnasal endoscopic prelacrimal recess approach (PLRA) in patients with maxillary sinus inverted papilloma (IP).

Methods We retrospectively analyzed 71 patients treated in our institution for maxillary sinus IP between August 2008 and April 2015. 20 patients underwent endoscopic surgery via PLRA. All the patients who had postoperative follow-up for 3 years were enrolled. Demographic data, surgical technique, location of IP attachment, intra- and postoperative complications, follow-up duration and recurrence were recorded.

Results The outpatient follow-up period was 3-10 years after surgery. Recurrence of IP was seen in $6(8.5 \%)$ of 71 patients, including 1 patient in the PLRA group. The recurrence rate was 5\% in the PLRA group. Six of 71 patients experienced postoperative complications, but none was observed in the PLRA group.

Conclusion Transnasal endoscopic PLRA is a minimally invasive, safe and effective method for maxillary sinus IP. The indication for PLRA is tumor pedicle located on the antero-inferior or infero-lateral wall or at multiple attachment sites of the maxillary sinus.
\end{abstract}

Keywords Transnasal endoscopic prelacrimal recess approach · Maxillary sinus $\cdot$ Inverted papilloma $\cdot$ Nasal cavity . Paranasal sinuses

\section{Introduction}

Inverted papilloma (IP) of the nasal cavity and paranasal sinuses is a benign tumor that accounts for $0.5-4 \%$ of all sinonasal tumors [1]. Two features of sinonasal IP are especially noteworthy: (1) it has a high propensity toward recurrence, with a recurrence rate of 5-30\%; and (2) it is associated with squamous cell carcinoma in 5-21\% of patients [2]. Therefore, aggressive surgical excision is the recommended treatment option. The maxillary sinus is the most frequent site of tumor origin (26-46.4\%) [3-5]. Despite advances in surgical techniques, the surgical approaches utilized to address tumors occurring in the maxillary sinus remain

$\mathrm{Na} \mathrm{Li}$

dr.lina@163.com

1 Department of Otolaryngology, Affiliated Hospital of Qingdao University, Qingdao, China

2 Center of Organ Transplantation, Affiliated Hospital of Qingdao University, Qingdao, China controversial. Because of the facial incision, the extranasal approach has a long healing time and inevitably forms scars after surgery, which has a negative impact on quality of life. With the development of nasal endoscopic and highresolution imaging techniques, nasal endoscopic surgery has become the most commonly used treatment for these diseases $[6,7]$. However, for anatomical reasons, the positions of the anterior and medial walls and the alveolar crypt of the maxillary sinus are not easily visible and manageable, therefore, it is difficult to perform the resection using the traditional endoscopic approach. Endoscopic medial maxillectomy is currently the gold standard for treatment of maxillary sinus IP. However, the procedure has numerous complications, such as epiphora, incrustation, and inability to feel the nasal airflow, due to resection of the nasolacrimal duct (NLD) and the inferior turbinate (IT). In 2007, Zhou et al. $[8,9]$ proposed the intranasal endoscopic prelacrimal recess approach (PLRA) to the maxillary sinus. This provides wide access to the walls and recesses of the maxillary sinus, while the IT and NLD are preserved [10]. 6 years ago, 
we adopted the PLRA to address maxillary sinus IP to avoid an external incisional wound. We performed a retrospective analysis of patients treated in our institution for maxillary sinus IP between August 2008 and April 2015. We aimed to determine the indication and effectiveness of transnasal endoscopic PLRA in patients with maxillary sinus IP.

\section{Methods}

\section{Patients}

This retrospective study was performed in 71 patients with histopathologically confirmed maxillary sinus IP who underwent surgery at the Department of Otolaryngology, Affiliated Hospital of Qingdao University, Shandong Province, China from August 2008 to April 2015. This study was approved by the Institutional Review Board of our hospital. Only adult patients with maxillary IP and with at least 3 years follow-up were considered eligible for inclusion. Patients with other sinonasal localizations of IP were excluded, along with patients with concomitant squamous cell carcinoma. All patients had preoperative computed tomography (CT) and magnetic resonance imaging (MRI) scans (Fig. 1), histopathological examination and outpatient assessment with nasal endoscopy. Demographic data, surgical technique, location of IP attachment sites, intra- and postoperative complications, follow-up duration, and recurrence were recorded.

\section{Surgical technique}

In all cases, surgery was performed under general anesthesia. Nasal mucosal blood vessels were contracted with $0.01 \%$ epinephrine gauze. Endoscopic examination confirmed the extent of the lesion. The endoscopic resection of the uncinate process, open and enlarge the ostium of the maxillary sinus. If pathological results were not obtained before surgery, the neoplasm in the maxillary sinus was taken for pathological examination by frozen section during surgery. After the pathological diagnosis of IP was established, the surgical approach was determined based on CT findings and the extent of the lesion seen during surgery. PLRA was selected for complicated
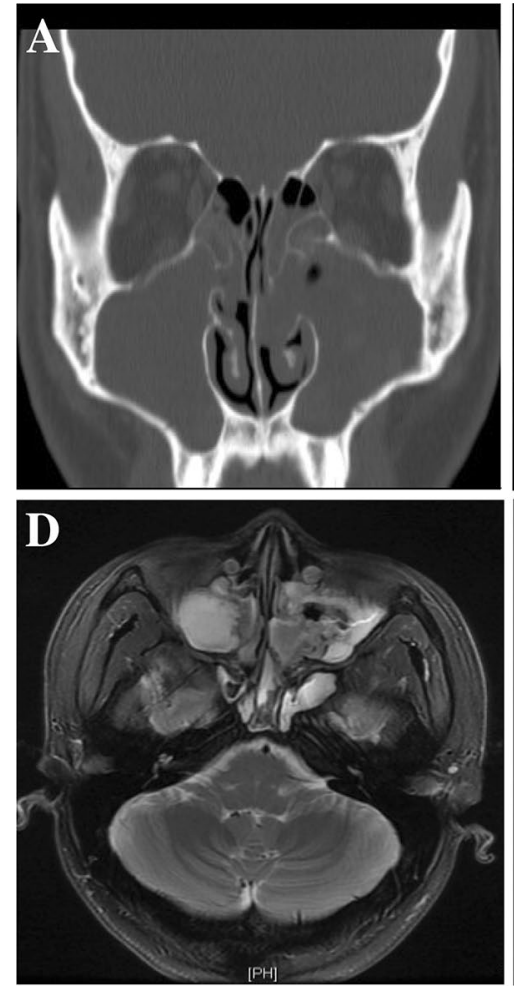
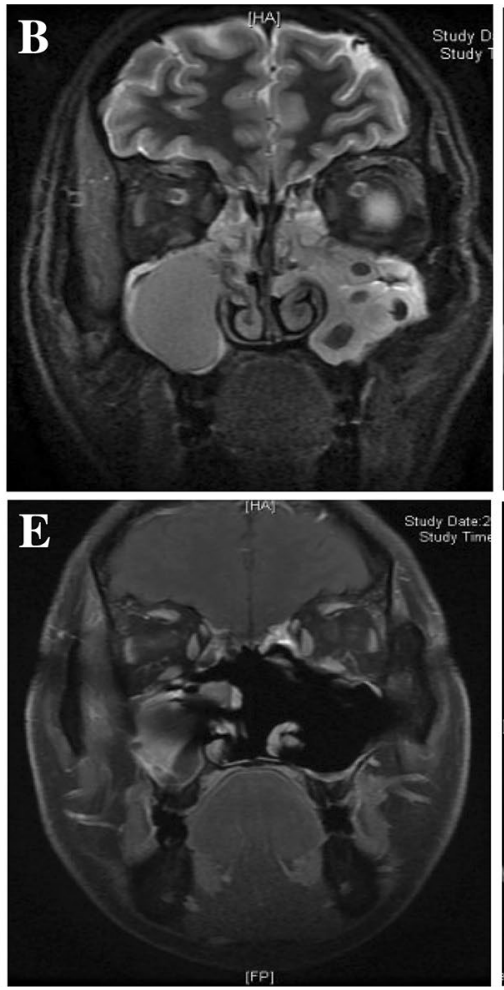
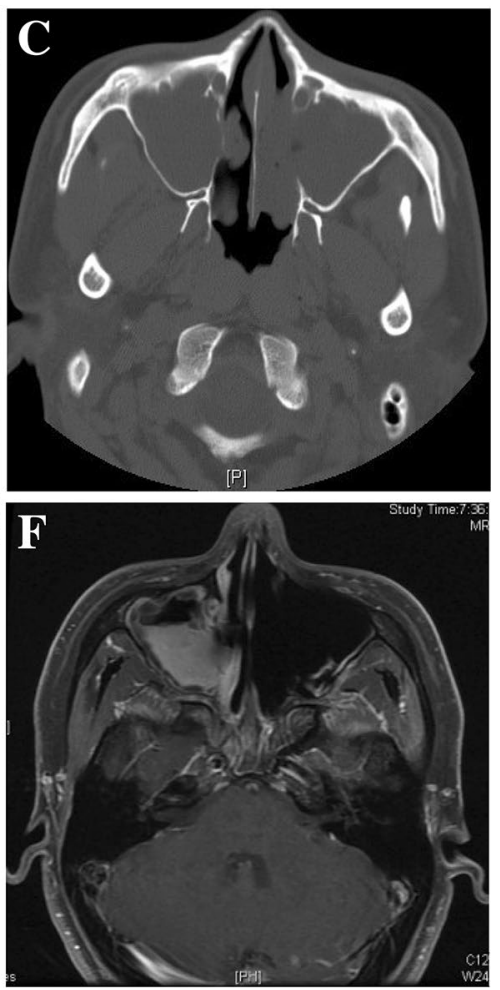

Fig. 1 Preoperative and postoperative paranasal sinus CT and MRI of IP of maxillary sinus. a Coronal CT demonstrated opacification of the bilateral maxillary sinus. b Coronal T2-weighted MR image with contrast showed IP as an intermediate and irregular mixed signal intensity mass of the left-side maxillary sinus. c Axial CT demonstrated opacification of the bilateral maxillary sinus. d Axial
T2-weighted MR image showed the tumor lying around the left-side maxillary sinus. e Postoperative coronal MRI showed a clear left and right maxillary sinus with thickened mucosa and no tumor recurrence. f Postoperative axial MRI showed a clear left and right maxillary sinus with thickened mucosa and no tumor recurrence 
IPs involving the alveolar crypts, prelacrimal recess, and antero-medial-inferior walls of the maxillary sinus, or with two or more root pedicles and with multiple areas of bone destruction in each wall of the maxillary sinus.

PLRA included the following surgical steps. The incision was infiltrated with $1 \%$ lidocaine with $1: 100,000$ epinephrine solution. A curved mucosal incision on the lateral wall of the nasal cavity was made between the anterior aspect of the inferior turbinate and the edge of the pyriform aperture to the bone (Fig. 2a). The mucosa from the subperiosteal level was elevated posteriorly to the insertion site of the inferior turbinate concha and then the bony attachment of IT was disconnected. The bony inferior orifice of NLD could be seen after the mucoperiostium was elevated posteriorly (Fig. 2b). We chiseled off the anterior bony portion of the medial wall of the maxillary sinus (part of the maxillary frontal process), and after chiseling the bone posteriorly, the NLD was exposed and the IT-NLD flap was formed (Fig. 2c). The IT-NLD flap was pushed medially and the antero-medial wall of the maxillary sinus was exposed (Fig. 2d). The maxillary sinus was entered through the antrostomy made at the prelacrimal recess (Fig. 2e). The maxillary sinus was exposed widely when the antrostomy was adequately enlarged, and all pathological tissues were removed under direct visualization (Fig. 2f). The IT-NLD mucosal flap was repositioned and the incision was sutured at the end of the operation (Fig. 2g).

\section{Follow-up}

Patients were endoscopically evaluated at 2 week and 1 , 2 and 3 months postoperatively, which included cleaning the crust and cysts, and then every 2-6 months, according to endoscopic findings and tailored to individual patient needs. Nasal irrigation with $0.9 \%$ sodium saline were also prescribed for at least 6 months. At the time of postoperative visit, if suspicious tumor tissue was found, histopathological biopsy or imaging examinations were performed timely.

\section{Results}

From August 2008 to April 2015, 71 patients were treated in our department for maxillary sinus IP. The average age of the patients at initial diagnosis was 52 years (range 25-76 years), with a male-to-female ratio of 1.63:1 (44 men and 27 women). Symptom onset occurred 1 week to 15 years before admittance to the hospital. The most frequent presenting symptom was nasal obstruction. This was followed by rhinorrhea or with blood and a feeling of pressure. A total of $29(40.8 \%)$ patients were considered to have had revised operation. The right side was more commonly involved than the left $(38 / 33,53.5 \%)$. Postoperative pathology was IP with mild dysplasia in 7 cases, moderate dysplasia in 2, and severe dysplasia in 1 . According to the Krouse classification method [11], 28 cases were grade II and 43 were grade III. 14 patients underwent endoscopic surgery via middle meatal antrostomy (MMA) of the maxillary sinuses. 30
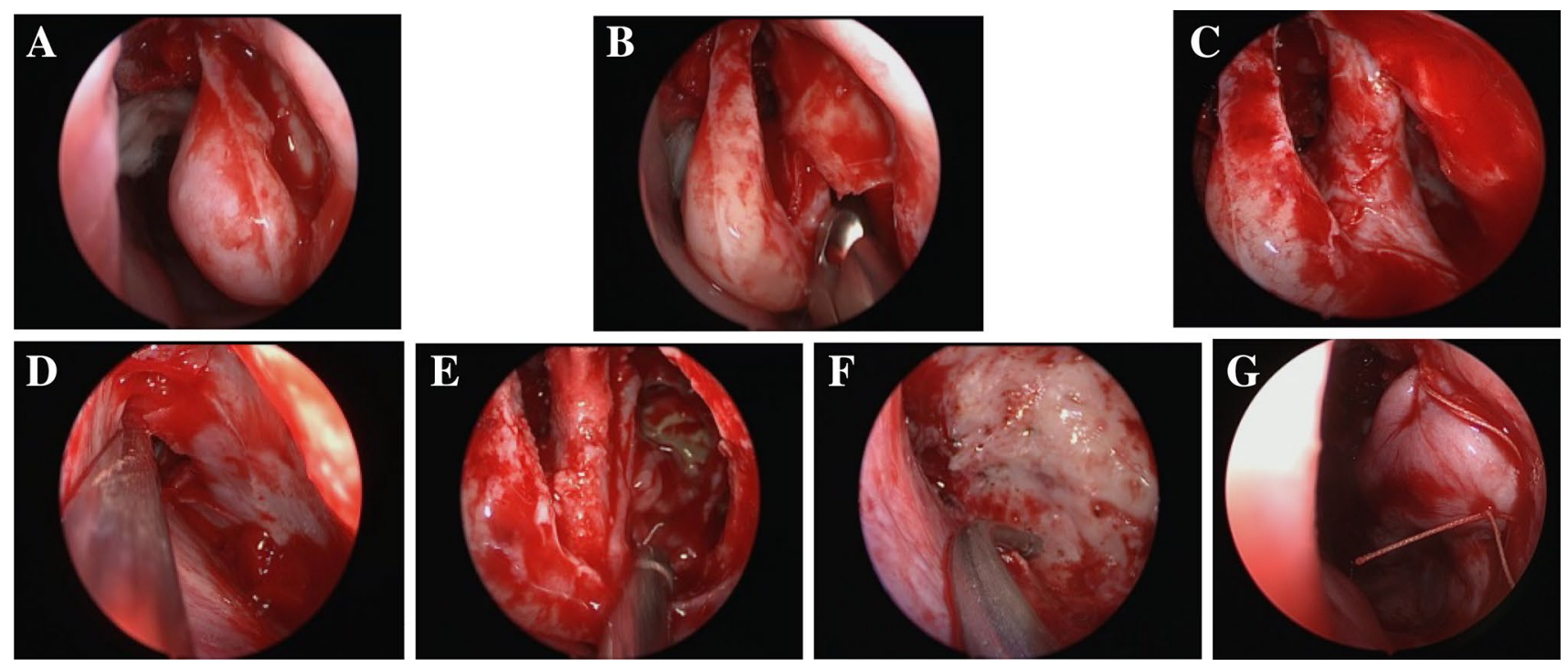

Fig. 2 Surgical procedures for the PLRA. a Curved mucosal incision on the lateral wall of the nasal cavity. b Mucoperiosteal flap was elevated to show lacrimal bone and inferior turbinate. c Nasolacrimal duct was released from its canal. d Antero-medial wall of maxillary sinus was exposed and the recess was widened. e Maxillary sinus was entered through the antrostomy made at the prelacrimal recess. $f$ The tumor was removed completely, and the tumor base was drilled. g ITNLD mucosal flap was repositioned and the incision was sutured 
patients underwent surgery via endoscopic medial maxillectomy (EMM), which comprised 23 simple EMMs (medial maxillary wall was resected into its posterior two-thirds) and 7 extended EMMs (NLD and IT were removed); 7 patients underwent surgery via endoscopic MMA combined with Caldwell-Luc surgery; and 20 patients underwent endoscopic surgery via PLRA (Table 1). The patients underwent surgery via PLRA mostly because tumors were present in the

Table 1 Postoperative complications and recurrence rate

\begin{tabular}{|c|c|c|c|c|c|}
\hline & MMA & $\mathrm{MMA}+\mathrm{LU}$ & $\begin{array}{l}\text { EMM } \\
\text { (sim- } \\
\text { ple) }\end{array}$ & $\begin{array}{l}\text { EMM } \\
\text { (extended) }\end{array}$ & PLRA \\
\hline No. of patients & 14 & 7 & 23 & 7 & 20 \\
\hline \multicolumn{6}{|l|}{ Complications } \\
\hline Epiphora & - & - & - & 1 & - \\
\hline $\begin{array}{c}\text { Periorbital } \\
\text { swelling }\end{array}$ & - & - & 1 & - & - \\
\hline $\begin{array}{l}\text { Facial numb- } \\
\text { ness }\end{array}$ & - & 1 & - & - & - \\
\hline Epistaxis & 1 & - & 1 & - & - \\
\hline Dry nose & - & - & - & 1 & - \\
\hline Recurrence & 2 & 1 & 2 & - & 1 \\
\hline
\end{tabular}

antero-inferior or infero-lateral wall or multiple attachment sites of the maxillary sinuses (Table 2).

Postoperative follow-up period was 3-10 years, with an average of 5.5 years. Of the 71 patients, $6(8.5 \%)$ had postoperative recurrence (Table 1). Four cases had recurrence within 2 years after surgery, and 1 within 5 years. Among the 20 patients with PLRA, 1 had recurrence (Table 2), in which the lesion was located on the anterior-medial wall of maxillary sinus cavity and recurred 8 months after surgery. During reoperation by nasal endoscopy, expanded resection of the lesion was performed and the bone at the base of the margin was adequately treated, and there was no recurrence after follow-up for 41 months.

6 of the 71 patients had postoperative complications (Table 1). After surgery by PLRA, there was no vision disorder, diplopia or epiphora; no facial numbness, pain or swelling; and no nasal complications such as dry nose. During surgery, the tumor was found to involve the NLD in one case. Thus, while preserving a 5-mm margin, the tumor tissue and the middle and lower parts of the NLD were resected together, and dacryocystorhinostomy was performed. At re-examination at 3 months after surgery, the operated cavity was completely epithelialized and no tumor recurred. In 4 cases, cystic vesicles or granuloma hyperplasia occurred in the operated cavity, which were removed by

Table 2 Patient demographic and clinical characteristics in the PLRA group

\begin{tabular}{|c|c|c|c|c|c|c|c|}
\hline Patient no. & Sex & Age (years) & Origin, wall (side) & $\begin{array}{l}\text { Revised } \\
\text { operation }\end{array}$ & $\begin{array}{l}\text { Follow-up } \\
\text { (months) }\end{array}$ & Complications & Recurrence \\
\hline 1 & M & 46 & MM, IM (R) & No & 37 & No & No \\
\hline 2 & M & 63 & MM, IM (L) & No & 37 & No & No \\
\hline 3 & M & 52 & $\mathrm{AM}(\mathrm{R})$ & No & 39 & No & No \\
\hline 4 & M & 58 & $\mathrm{MM}(\mathrm{L})$ & No & 41 & No & No \\
\hline 5 & $\mathrm{~F}$ & 62 & $\mathrm{AM}, \mathrm{MM}(\mathrm{L})$ & No & 44 & No & No \\
\hline 6 & $\mathrm{~F}$ & 47 & $\mathrm{AM}, \mathrm{MM}(\mathrm{R})$ & Yes & 44 & No & No \\
\hline 7 & $\mathrm{~F}$ & 76 & MM, LM, IM (L) & Yes & 46 & No & No \\
\hline 8 & $\mathrm{~F}$ & 51 & MM, PM (L) & Yes & 47 & No & No \\
\hline 9 & M & 36 & $\mathrm{AM}, \mathrm{MM}(\mathrm{R})$ & No & 49 & No & 8 months after surgery \\
\hline 10 & M & 51 & MM, AM, IM (R) & No & 51 & No & No \\
\hline 11 & M & 78 & $\mathrm{MM}, \mathrm{AM}(\mathrm{R})$ & Yes & 54 & No & No \\
\hline 12 & M & 60 & Whole wall (R) & No & 55 & No & No \\
\hline 13 & $\mathrm{M}$ & 37 & LM, IM (R) & Yes & 57 & No & No \\
\hline 14 & M & 67 & PM, IM (R) & No & 57 & No & No \\
\hline 15 & $\mathrm{M}$ & 73 & AM, IM, MM (L) & Yes & 58 & No & No \\
\hline 16 & $\mathrm{~F}$ & 57 & Whole wall (L) & Yes & 61 & No & No \\
\hline 17 & $\mathrm{~F}$ & 47 & AM, MM, IM (R) & Yes & 65 & No & No \\
\hline 18 & M & 50 & MM, IM (R) & Yes & 68 & No & No \\
\hline 19 & $\mathrm{M}$ & 56 & MM, AM (L) & No & 70 & No & No \\
\hline 20 & M & 62 & $\mathrm{AM}(\mathrm{L})$ & Yes & 73 & No & No \\
\hline
\end{tabular}

$S M$ superior wall of the maxillary sinus, $P M$ posterior wall of the maxillary sinus, $M M$ medial wall of the maxillary sinus, $L M$ lateral wall of the maxillary sinus, $A M$ anterior wall of the maxillary sinus, $I M$ inferior wall of the maxillary sinus, $R$ right, $L$ left 
nasal endoscopy, and disappeared 2-4 weeks after flushing the nasal cavity, and no recurrence was found. Stenosis of the middle meatal antrostomy and scarification were observed in 2 IP cases.

\section{Discussion}

Due to the restriction of the maxillary sinus anatomy and the characteristics of tumor biological behavior, the recurrence rate of maxillary sinus IP after surgery under nasal endoscopy is still high. IP that originates in the maxillary sinus, due to the delayed appearance of symptoms, has a relatively great extent of tumor. Our experience shows that it is important to search carefully for and locate the origin of the tumor under nasal endoscopy. The tumor origin of IP in the nasal cavity and sinuses has a high degree of consistency with bone hyperplasia in CT imaging [12], and the precise location of the lesion can be determined in conjunction with endoscopic findings. Choosing a reasonable surgical procedure based on the location and extent of the lesion reduces both the recurrence rate and surgical complications.

In the present study, 14 patients with the bases of tumors confined to the posterior-lateral wall of the maxillary sinus, but far posteriorly, underwent surgery with expanded MMA. Two cases had recurrence after surgery, but no obvious complications were observed. For the patients with IP that originated in the medial wall of the maxillary sinus with significant bone destruction, poor differentiation, or dysplasia, complete resection of the medial wall of the maxillary sinus was performed. This approach can expose the entire maxillary sinus and completely remove the tumor, but the need to remove the IT and NLD results in major trauma. In the present series of patients, one had epiphora and another had dry nose. Seven patients whose tumor was located in the anterior, medial and inferior walls of the maxillary sinus, underwent MMA combined with Caldwell-Luc surgery. After fully expanding the natural opening of the maxillary sinus, an incision in labiogingival groove was made, but postoperative complications such as facial numbness or tooth pain were recorded. According to our experience, the lesions are fully exposed by this approach, but the wounds are larger. This approach has gradually been replaced by the PLRA in our department.

Studies have been carried out in the surgical approach for this disease. Weber et al. [13] reported a case series of 12 patients with IP of the maxillary sinus (Krouse II-III) who were endoscopically treated with medial maxillectomy with IT preservation. There was no recurrence of tumor after 12-80 months. Nakamura et al. [14] reported a method with the preservation of the NLD during EMM for IP. However, if the tumor was attached to the bottom of maxillary sinus with irregular prominences, it was difficult to manage intranasally by this method. Tewfik et al. [15] recommended canine fossa puncture to remove the complex lesions in the maxillary sinus cavity. Because the ring drilling point is located on the outer tip of the root of the canine tooth and the upper alveolar nerve may be damaged, there may still be complications after surgery, such as numbness in the upper lip and cheeks, numbness of the teeth, and cheek pain and swelling.

The advantages of PLRA are that it can be performed completely in the nasal cavity. Nasal endoscopy at $0^{\circ}$ can obtain a good visual field; the lesions in the maxillary sinus are fully exposed, leaving no blind angle, which facilitates complete removal of the lesions. Through displacement, the NLD and IT are protected and the function of the nasal cavity and NLD is thus maintained. At the same time, PLRA can avoid additional incisions, and avoid damage to the anterior maxilla wall and to the infraorbital nerve and upper alveolar nerve. This also avoids postoperative occurrence of other complications such as pain and swelling in the upper lip and cheek, tooth numbness, and cheek numbness. However, the disadvantage is that the NLD needs to be protected during surgery. Therefore, there is a high need of surgeon's anatomical knowledge and proficiency in nasal endoscopic surgery.

Conclusion, the key to successful surgery by the PLRA lies in the following aspects. The extent of the lesion needs to be confirmed and the operative field needs to be managed. Imaging should be performed before surgery to determine the extent and features of the lesion. We are in favor of performing MMA before PLRA because it provides a better drainage route for the maxillary sinus and wider access to the maxillary sinus for postoperative treatment. During surgery, the tumor tissue and surrounding mucosa should be removed together for the better prevention of postoperative recurrence. The bone hyperplasia in the basal part of the tumor needs to be removed with a bone chisel or drill [16]. The occurrence of adverse reactions must be avoided during surgery [17]. The PLRA achieves the exposure range of medial maxillectomy and the Caldwell-Luc surgery, and retains the integrity of the IT and lacrimal duct system. While fully exposing the tumors for complete removal, the nasal function is well protected. In most cases, the PLRA can replace the Caldwell-Luc surgery and is an ideal surgical method in treating maxillary sinus IP under endoscopy. The sample size in our study was small, and a larger group with extended follow-up is required to verify the effectiveness of the protocol.

Acknowledgements This work was funded by Shandong Procincial Natural Science Foundation, China (ZR2016HB66). 


\section{Compliance with ethical standards}

Conflict of interest The authors declare that they have no conflict of interest.

Ethical approval All procedures performed in studies involving human participants were in accordance with the ethical standards of the institutional and national research committee and with the 1964 Helsinki declaration and its later amendments or comparable ethical standards. This study was approved by the Institutional Review Board of the Affiliated Hospital of Qingdao University, Shandong, China.

Informed consent This was a retrospective review and thus, informed consent was not required by our human ethics board.

Open Access This article is distributed under the terms of the Creative Commons Attribution 4.0 International License (http://creativeco mmons.org/licenses/by/4.0/), which permits unrestricted use, distribution, and reproduction in any medium, provided you give appropriate credit to the original author(s) and the source, provide a link to the Creative Commons license, and indicate if changes were made.

\section{References}

1. Lund VJ, Stammberger H, Nicolai P et al (2010) European position paper on endoscopic management of tumours of the nose, paranasal sinuses and skull base. Rhinol Suppl 22:1-143

2. Gu FM, Zhang LS (2014) Clinical outcomes of endoscopic and open resection of recurrent sinonasal inverted papilloma. J Craniofac Surg 25:1090-1093. https://doi.org/10.1097/scs.0000000000 000560

3. Wormald PJ, Ooi E, van Hasselt CA, Nair S (2003) Endoscopic removal of sinonasal inverted papilloma including endoscopic medial maxillectomy. Laryngoscope 113:867-873. https://doi. org/10.1097/00005537-200305000-00017

4. Pagella F, Giourgos G, Matti E, Canevari FR, Carena P (2011) Endoscopic treatment of maxillary inverted papilloma. Rhinology 49:369-374. https://doi.org/10.4193/Rhino10.132

5. Pagella F, Pusateri A, Matti E, Tomacelli GL (2017) "TuNasaving" endoscopic medial maxillectomy: a surgical technique for maxillary inverted papilloma. Eur Arch Otorhinolaryngol 274:2785-2791. https://doi.org/10.1007/s00405-017-4549-0
6. Kamel RH (1992) Conservative endoscopic surgery in inverted paplloma. Preliminary report. Arch Otolaryngol Head Neck Surg 118:649-653. https://doi.org/10.1001/archotol.1992.0188006009 9020

7. Waltz G, Wigand ME (1992) Results of endoscopic sinus surgery for the treatment inverted papillomas. Laryngoscope 102:917922. https://doi.org/10.1288/00005537-199208000-00012

8. Zhou B, Han DM, Cui SJ, Wang CS (2013) Intranasal endoscopic prelacrimal recess approach to maxillary sinus. Chin Med J (Engl) 126:1276-1280. https://doi.org/10.3760/ cma.j.issn.0366-6999.20121754

9. Zhou B, Han DM, Cui SJ, Liu M (2007) Endoscopic nasal lateral wall dissection approach to maxillary sinus. Zhonghua Er Bi Yan Hou Tou Jing Wai Ke Za Zhi 42:743-748. https://doi. org/10.3760/j.issn:1673-0860.2007.10.006

10. Morrissey DK, Wormald PJ, Psaltis AJ (2016) Prelacrimal approach to the maxillary sinus. Int Forum Allergy Rhinol 6:214 218. https://doi.org/10.1002/alr.21640

11. Krouse JH (2000) Development of a staging system for inverted papilloma. Laryngoscope 110:965-968. https://doi. org/10.1097/00005537-200006000-00015

12. Lee DK, Chung SK, Dhong HJ, Bok HK (2007) Focal hyperostosis on $\mathrm{CT}$ of sinonasal inverted papilloma as a predictor of tumor origin. Am J Neuroradiol 28:618-621

13. Weber RK, Werner JA, Hildenbrand T (2010) Endonasal endoscopic medial maxillectomy with preservation of the inferior turbinate. Am J Rhinol Allergy 24:132-135. https://doi.org/10.2500/ ajra.2010.24.3531

14. Nakamaru Y, Furuta Y, Takagi D, Oridate N, Fukuda S (2010) Preservation of the nasolacrimal duct during endoscopic medial maxillectomy for sinonasal inverted papilloma. Rhinology 48:452-456. https://doi.org/10.4193/Rhino10.015

15. Tewfik MA, Wormald PJ (2010) Planning for the canine fossa trephination approach. Oper Tech Otolaryngol Head Neck Surg 21:150-154. https://doi.org/10.1016/j.otot.2010.06.001

16. Healy DY, Chhabra N, Metson R, Gray ST (2015) Surgical risk factors for recurrence of inverted papilloma. Laryngoscope 126:796-801. https://doi.org/10.1002/lary.25663

17. Lin YT, Lin CF, Yeh TH (2018) Application of the endoscopic prelacrimal recess approach to the maxillary sinus in unilateral maxillary diseases. Int Forum Allergy Rhinol 8:530-536. https:// doi.org/10.1002/alr.22062 